\title{
Nanocomposite Synthesis of Nanodiamond and Molybdenum Disulfide
}

\author{
Youngjun Kim, Dukhee Lee, Soo Young Kim® ${ }^{\circledR}$, Eunah Kang * and Chang Keun Kim * \\ School of Chemical Engineering and Material Science, Chung-Ang University, Seoul 06974, Korea \\ * Correspondence: ckkim@cau.ac.kr (C.K.K.); eakangek@cau.ac.kr (E.K.); \\ Tel.: 82)-2-820-5324 (C.K.K.); 82)-2-820-6684 (E.K.)
}

Received: 7 June 2019; Accepted: 26 June 2019; Published: 27 June 2019

check for updates

\begin{abstract}
A chemically conjugated nanodiamond (ND)/MoS 2 nanocomposite was synthesized with amine-functionalized $\mathrm{MoS}_{2}$ and acyl chloride-coordinated ND. The chemical structure and morphology of the nanocomposite were characterized to examine the dispersion of $\mathrm{MoS}_{2}$ on the ND platform. The results revealed that the degree of dispersion was enhanced with increasing ratio of $\mathrm{MoS}_{2}$ nanosheets to ND. Moreover, the nanosheets consisted of several molecular interlayers that were well-dispersed on the ND platform, thereby forming a nanophase. The efficient electrocapacity of the ND/MoS 2 nanocomposite was considerably greater than that of the $\mathrm{MoS}_{2}$ electrode alone. Furthermore, the nanophase distribution of $\mathrm{MoS}_{2}$ on ND with a graphitic shell provided a large surface area and reduced the diffusion distance of ions and electrons. Therefore, the nanophase electrode showed higher electrochemical capacitance than that of the $\mathrm{MoS}_{2}$ electrode alone.
\end{abstract}

Keywords: nanocomposite; $\mathrm{MoS}_{2}$; nanodiamond

\section{Introduction}

Numerous novel materials and composites including two-dimensional (2D) materials have been exploited with the aim of enhancing electrocapacity, which can be applied for biosensing platforms and electrocatalytic performance. A 2D layered material can be defined as an unsupported crystalline solid with molecular layer thickness characterized by intralayer storage for heat, charge, and light transport [1-4]. This transport occurs in the presence of intralayer covalent bonds and intercalation-based interaction [5]. Specifically, $\mathrm{MoS}_{2}$ as a 2D transition metal dichalcogenide (TMD) exhibits the unique characteristic of charge confinement in the 2D layer in the absence of interlayer interaction along the z-axis [6]. Functional features of $2 \mathrm{D} \mathrm{MoS}_{2}$ layers include high thermal and chemical stability for functionalization [7,8], large surface area [4], good mobility [9], and intercalation-based physical interaction $[10,11]$. For final functional performance, the construction of an electrode and nanophase distribution of an aggregation-free $2 \mathrm{D} \mathrm{MoS}_{2}$ molecular layer are critical to induce maximal functional features.

Carbon-based materials including fullerenes, graphene, and carbon nanotubes, are considered as fundamental platform materials of energy conversion and storage, owing to their thermal stability, conductivity, and mechanical properties [12-15]. Furthermore, the electron buffering capability of these materials stems from their high surface-to-volume ratio and the unsaturated carbon $\sqcap$ bonds. Physicochemical characteristics can reduce oxygen adsorption on a catalyst surface, thereby improving the material performance. In general, the porous structure of carbon materials is characterized by a multiscale nanocage and a high surface-to-volume ratio that provide electron transfer and electrocatalytic active sites. These advantages have often been applied to nanocomposites with metal to induce synergistic functional effects, including solar cells, batteries, and supercapacitors [16-20]. 
Nanodiamonds (NDs) among carbon platforms have received less attention than some of the other carbon materials due to the high costs and low conductivity of these materials as electric functional materials [21,22]. However, NDs possess excellent physical properties, including high adsorption [23], high surface-to-volume ratio [24], chemical modality on the graphitic shell surface [25], and a nanocage within agglutinate [26]. Moreover, the dispersive capability of NDs in aqueous environments makes it possible to integrate and to extend materials to other functional employment, including biomedical applications as well as electronic functions [27]. NDs serve as a supporting platform that can augment the functional efficiency of the other incorporated pair of 2D materials.

Therefore, in this study a $\mathrm{ND} / \mathrm{MoS}_{2}$ nanocomposite by subsequent functionalization was synthesized and characterized. An ND with a graphitic shell around its surface provides stable sites for chemical modification. Immediate chemical reaction between the acyl chloride of NDs and amine-functionalized $\mathrm{MoS}_{2}$ was intended to form aggregation-free $\mathrm{MoS}_{2}$ nanosheet dispersion on the ND support (Scheme 1). This nanophase dispersion of $\mathrm{MoS}_{2}$ in several interlayers on the ND platform was examined from the viewpoint of physical characteristics and potential electrofunctionality.

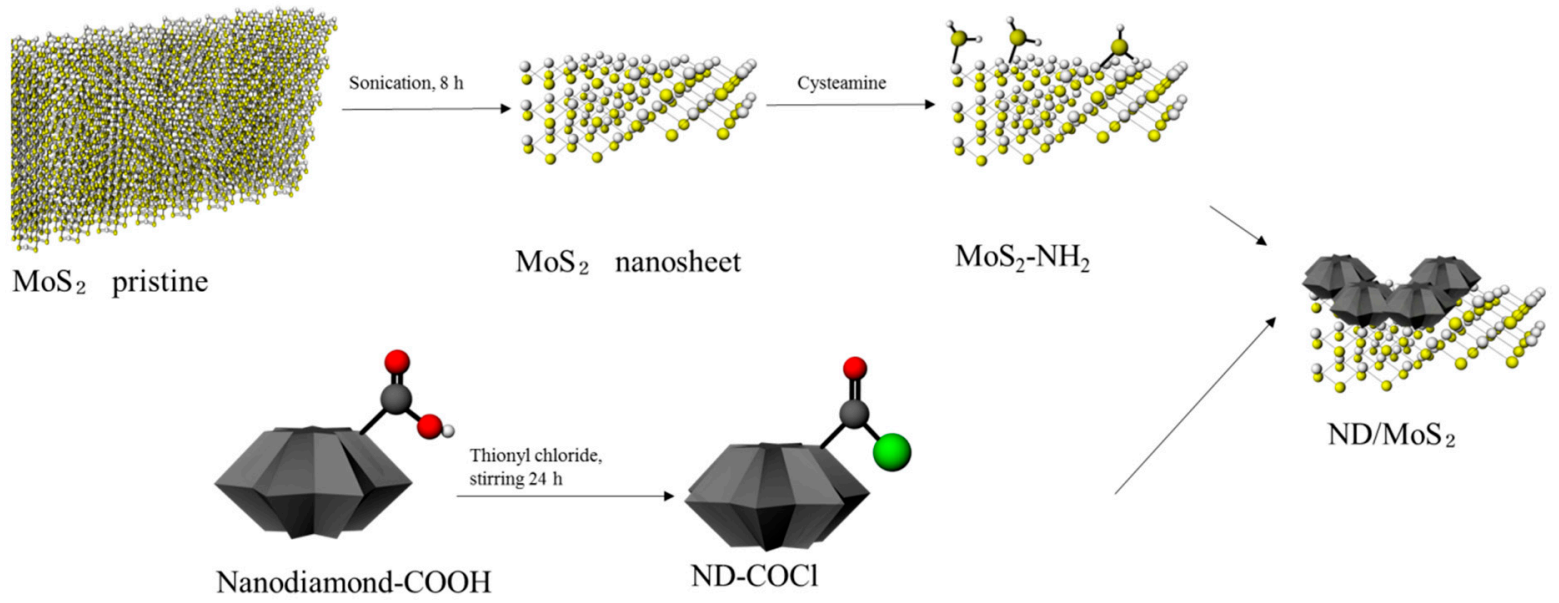

Scheme 1. Schematic showing conformation of the nanodiamond (ND)/MoS 2 nanocomposites.

\section{Experimental Methods}

\subsection{Nanocomposite Formation of $\mathrm{MoS}_{2}$ and Nanodiamonds}

ND-COOHs (40 mg) gifted from Nanoresource (Seoul, Korea) were mixed with $100 \mathrm{~mL}$ of thionyl chloride (Samcheon Chemical Co., Seoul, Korea) and $0.5 \mathrm{~mL}$ of dimethylformamide anhydrous (DMF) in a $250 \mathrm{~mL}$ round-bottomed flask. The ND-COOHs were well-dispersed for $15 \mathrm{~min}$ of bath sonication under an ice bath. The ND dispersion for acylation was stirred for $24 \mathrm{~h}$ at $70{ }^{\circ} \mathrm{C}$ under a $\mathrm{N}_{2}$ purge. After reaction, the dispersion was washed repeatedly five times with tetrahydrofuran anhydrous (THF) and the NDs, separated by centrifugation, were dried at $60{ }^{\circ} \mathrm{C}$ in an air-circulated oven.

For exfoliation, the mixture of pristine $\mathrm{MoS}_{2}(120 \mathrm{mg},<2 \mu \mathrm{m}$; Sigma-Aldrich Chemicals, St Louis, MO, USA) and N-vinyl-2-pyrrolidone $(60 \mathrm{~mL})$ was sonicated with condition of $55 \%$ power amplitude and $3 \mathrm{~s}$ pulse (VC750, Sonics Vibra-cell) for $8 \mathrm{~h}$ under circulation at $7{ }^{\circ} \mathrm{C}$ [28]. After exfoliation, the large $\mathrm{MoS}_{2}$ was separated by centrifugation (4000 rpm, $5 \mathrm{~min}$ ), and the supernatant was extracted. This supernatant was then filtered through a syringe filter $(0.45 \mu \mathrm{m}, \mathrm{HP} 045 \mathrm{AN}$, Advantec, Taipei, Taiwan) and centrifuged (14,600 rpm, $10 \mathrm{~min}$ ). Afterward, the settled $\mathrm{MoS}_{2}$ nanosheets were washed with isopropanol and centrifuged repeatedly until the yellow color of $\mathrm{N}$-vinyl-2-pyrrolidone became colorless. The nanosheets were then dried for $24 \mathrm{~h}$ at $40^{\circ} \mathrm{C}$ under vacuum.

The $\mathrm{MoS}_{2}$ nanosheets $(1 \mathrm{mg} / \mathrm{mL})$ were dispersed in DMF. For chemical conjugation, $200 \mu \mathrm{L}$ of cystamine $(5 \mathrm{mg} / \mathrm{mL})$ in DMF was added to $1 \mathrm{~mL}$ of the $\mathrm{MoS}_{2}$ dispersion. This dispersion mixture was then sonicated for $1 \mathrm{~h}$ under an ice bath. After sonication, the mixture was left to stand at room 
temperature for $24 \mathrm{~h}$. Then, functionalized $\mathrm{MoS}_{2}$ was washed repeatedly three times with DMF, separated by centrifugation at $14,600 \mathrm{rpm}$, and completely dried at $60^{\circ} \mathrm{C}$ in a vacuum oven.

Acylated NDs $(1 \mathrm{mg} / \mathrm{mL})$ and amine-functionalized $\mathrm{MoS}_{2}$ nanosheets in DMF were dispersed with $5 \mathrm{~min}$ of bath sonication. The dispersion of acylated ND and amine-functionalized $\mathrm{MoS}_{2}$ with desired ratios $(1: 1,1: 2,1: 4$, and 1:8) was mixed by sonication under an ice bath for $30 \mathrm{~min}$, and shaken with a vortex for $24 \mathrm{~h}$. After the reaction, the composite was washed and completely dried at $60{ }^{\circ} \mathrm{C}$ in a vacuum oven.

\subsection{Characterization of $\mathrm{ND} / \mathrm{MoS}_{2}$ Nanocomposites}

The ultraviolet (UV) absorption of ND-COCl, $\mathrm{MoS}_{2}$ nanosheet, and ND/MoS 2 nanocomposite was measured with a V-670 UV-Vis/NIR spectrophotometer (JASCO Corp., Tokyo, Japan). These measurements were performed under the following conditions: scanning speed: $200 \mathrm{~nm} / \mathrm{min}$, data interval: $1 \mathrm{~nm}, \mathrm{UV}$-Vis bandwidth: $1.0 \mathrm{~nm}$, near-infrared (NIR) bandwidth: $2.0 \mathrm{~nm}$, and wavelength: 350-900 nm [29]. The dispersions $(0.2 \mathrm{mg} / 2 \mathrm{~mL})$ of the nanosheets and the nanocomposite in deionized (DI) water were placed, respectively, in a synthetic quartz cuvette (light path: $1 \mathrm{~cm}$, Hellma Analytics, Müllheim, Germany). Measurement of Fourier transform infrared spectroscopy (FT-IR; Nicolet 6700, Thermo Scientific., Waltham, MA, USA) ranged from $4000-500 \mathrm{~cm}^{-1}$ of wavelength and was performed subsequently on the chemical reactant, $\mathrm{ND}$, and $\mathrm{MoS}_{2}$. IR samples were prepared using the standard method of $\mathrm{KBr}$ pellet (7 mm in diameter). The materials of $0.5-1 \mathrm{mg}$ were added with a portion of $\mathrm{KBr}$ (7 mg).

X-ray photoeletron spectroscopy (XPS; ThermoFisher Scientific Co., Waltham, MA, USA) measurements were also conducted with an Al K $\alpha$ energy source. The spectra were analyzed using Avantage software (version 1.6, Thermo Fisher Scientific, Waltham, MA, USA). Transmission electron microscopy (TEM) images were obtained with a JEM-2100F electron microscope (JEOL, Tokyo, Japan). For sample preparation, $10 \mu \mathrm{L}$ each of ND, $\mathrm{MoS}_{2}$, and ND/MoS 2 nanocomposite was dropped on Formvar/Carbon on a 200 mesh grid (TED PELLA Co., Redding, CA, USA.) and dried for 10 min at $60{ }^{\circ} \mathrm{C}$ in an oven.

\subsection{Cyclic Voltammetry (CV) Measurements}

A dispersion of $\mathrm{ND} / \mathrm{MoS}_{2}$ nanocomposite $(1 \mathrm{mg} / \mathrm{mL})$ was prepared in Nafion solution $(0.5 \%$ in DI water) for electrode fabrication. Droplets of the dispersion $(10 \mu \mathrm{L})$ were placed on the glassy carbon working electrode (diameter $3 \mathrm{~mm}$ ) and dried at $80{ }^{\circ} \mathrm{C}$ for $1 \mathrm{~h}$. Cyclic voltammetry (CV) measurements (potential: -0.8 to $0.2 \mathrm{~V}$, scan rate: -0.2 to $1.0 \mathrm{~V}$ ) were performed using a three-electrode system (reference electrode: $\mathrm{Ag} / \mathrm{AgCl}$, counter electrode: platinum wire (57 mm in length, OD $0.5 \mathrm{~mm}$ ), working electrode: $\mathrm{ND} / \mathrm{MoS}_{2}$ or $\mathrm{MoS}_{2}$ deposited glassy carbon electrode). Two sets of measurements using a potensiostat (DY2322, Digi-Ivy, Austin, TX, USA) were also performed at potentials ranging from 0.05 to $0.5 \mathrm{~V} \cdot \mathrm{s}^{-1}$ and scan rates of $0.05,0.1$, and $0.5 \mathrm{~V} / \mathrm{s}$. The corresponding $\mathrm{CV}$ plots were recorded in a $0.1 \mathrm{M} \mathrm{KOH}$ solution $(15 \mathrm{ml})$. Five cycles in 2 sets were performed to obtain a voltamogram. After stabilization from repeated cycles, an oxidation and reduction curve in each second set of a working electrode was shown for data presentation.

\section{Results and Discussion}

UV-vis absorption spectra were obtained for the $\mathrm{MoS}_{2}$ nanosheets, ND-COCl, and ND/MoS 2 nanocomposite with ratios of 1:1, 1:2, 1:4, and 1:8 (Figure 1). Typical $\mathrm{MoS}_{2}$ excitation absorption peaks, which occurred at 630 and $690 \mathrm{~nm}$, were attributed to the direct gap transitions at the $\mathrm{K}$ point [30-32]. These indicate the lowest optical band gap of the $\mathrm{MoS}_{2}$ nanosheets (i.e., $1.8 \mathrm{eV}$ ) that were changed, owing to the quantum confinement in the sheets. Changes in the UV absorbance were evaluated for the $\mathrm{MoS}_{2} / \mathrm{ND}$ nanocomposite with ratios of 1:1 to 1:8. The optical absorbance peaks of $\mathrm{MoS}_{2} / \mathrm{ND}$ nanocomposite appeared in the same region as those of the $\mathrm{MoS}_{2}$ nanosheets. It was indicated that chemically conjugated $\mathrm{MoS}_{2} / \mathrm{ND}$ nanocomposite maintained the optical characteristics 
of the nanosheets. The intensity of the bands in the spectra were augmented with the increasing ratio of the nanocomposite, as shown in Figure 1 [33].

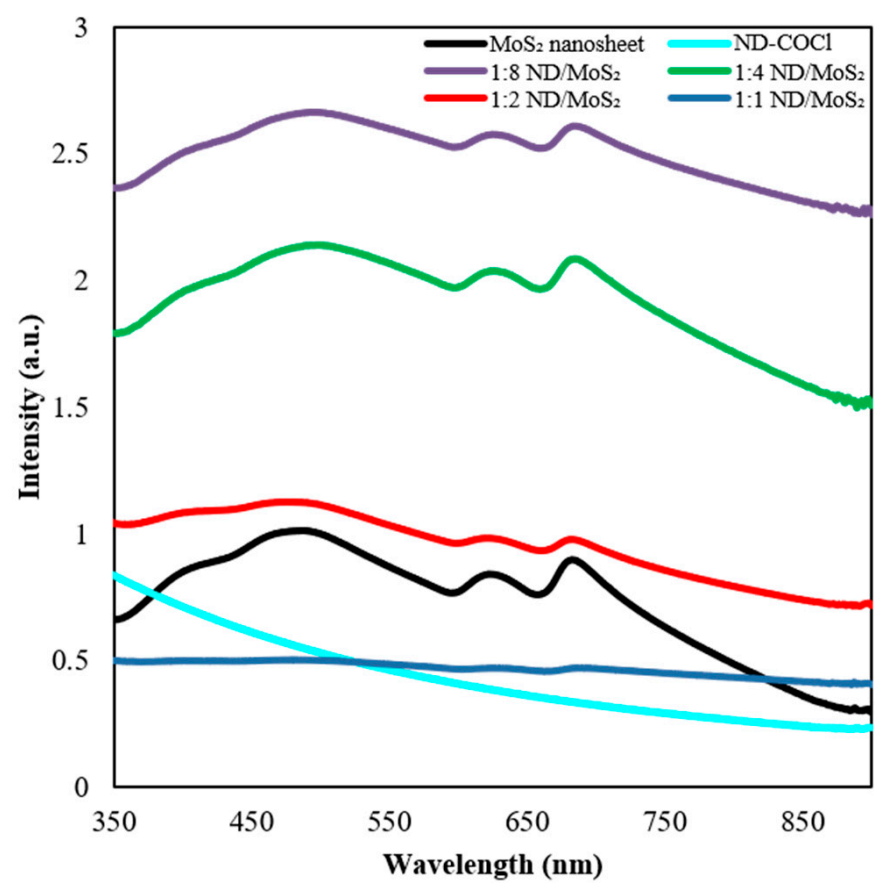

Figure 1. UV-vis absorbance spectra of $\mathrm{MoS}_{2}$ nanosheets, ND, and ND/MoS 2 nanocomposites with ratios of $1: 1,1: 2,1: 4$, and $1: 8$.

Chemical conjugation of the nanocomposite and functional groups of intermediate products was characterized via FT-IR spectroscopy to identify sequential chemical modification of the acyl chloride comprising $\mathrm{ND}(\mathrm{ND}-\mathrm{COCl}), \mathrm{MoS}_{2}-\mathrm{NH}_{2}$, and $\mathrm{MoS}_{2} / \mathrm{ND}$ nanocomposites (Figure 2). The oxidative treatment formed a carbonyl group $(\mathrm{C}=\mathrm{O})$ and a hydroxyl group $(-\mathrm{OH})$, occurring as absorption peaks at 1718 and $3400 \mathrm{~cm}^{-1}$ on the surface of the carboxylated ND, respectively. The graphitic shell around the crystalline ND was attributed to the absorption bands associated with $\mathrm{C}=\mathrm{C}$ bond bending at $1625 \mathrm{~cm}^{-1}$. After acyl chlorination, ND with an acyl chloride bond $(\mathrm{C}-\mathrm{Cl})$ was formed, corresponding to the stretching peak at $593 \mathrm{~cm}^{-1}$, whereas no peak for ND-COOH was observed [34]. The results indicated that the carboxylated ND surface was activated by the acyl chloride group for an amine reactive reaction. The functionalization of $\mathrm{MoS}_{2}$ with cysteamine hydrochloride was characterized with comparison of the cysteamine hydrochloride. For the amine-functionalized $\mathrm{MoS}_{2}$, an $\mathrm{N}-\mathrm{H}$ deformation vibration peak and an $\mathrm{NH}_{2}$ stretching vibration peak, derived from the chemical conjugation with cysteamine hydrochloride, occurred at 1604 and $3390 \mathrm{~cm}^{-1}$, respectively [35]. This indicated the successful modification of amine-functionalized $\mathrm{MoS}_{2}$, where amine groups were positioned on the surface of $\mathrm{MoS}_{2}$ nanosheets. The formation of an amide bond (NHCO) between the acyl chloride of $\mathrm{ND}$ and the functionalized $\mathrm{MoS}_{2}$ nanosheets was confirmed via FT-IR spectroscopy of the ND/MoS 2 nanocomposites. The spectra obtained for the nanocomposites exhibited characteristics of both $\mathrm{ND}-\mathrm{COCl}$ and the functionalized nanosheets. The absorption bands associated with the ND/MoS 2 peak were attributed to hydroxyl bond stretching and an amide bond (NHCO) at $3400 \mathrm{~cm}^{-1}$ and $1632 \mathrm{~cm}^{-1}$, respectively. Furthermore, the relatively strong absorbance band region resulted probably from the overlapping of bands associated with $\mathrm{C}=\mathrm{C}$ vibration and $\mathrm{C}=\mathrm{O}$ stretching [36,37]. 


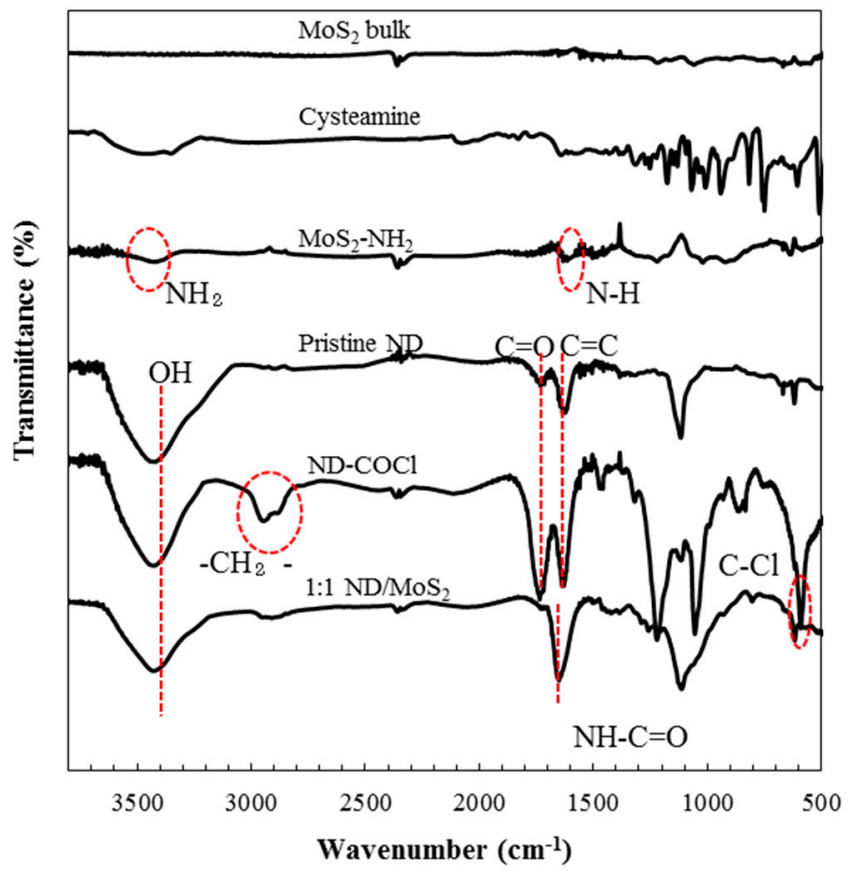

Figure 2. FT-IR spectra of the $\mathrm{MoS}_{2}$ bulk, cysteamine, amine-functionalized $\mathrm{MoS}_{2}\left(\mathrm{MoS}_{2}-\mathrm{NH}_{2}\right)$, carboxylated ND, acyl chloride of ND, and ND/MoS 2 nanocomposite with ratio of 1:1.

The chemical structure of the ND/MoS 2 nanocomposite, compared with that of ND-COCl, was determined from the measured XPS spectra, as shown in Figure 3a-f. The $\mathrm{C} 1 \mathrm{~s}$ peaks of ND-COCl and $\mathrm{ND} / \mathrm{MoS}_{2}$ were decon-voluted into four component peaks using Gaussian fitting at 284.8 (C-C), 286.0 $(\mathrm{C}-\mathrm{O}), 287.2(\mathrm{C}=\mathrm{O})$, and $289(-\mathrm{COOH}) \mathrm{eV}$, respectively $[38,39]$. The $\mathrm{C}=\mathrm{O}$ peak at $287.2 \mathrm{eV}$ for ND-COCl was generated from both acyl chloride and some portion of the carboxyl group. The $\mathrm{C}=\mathrm{O}$ peak at 287.2 $\mathrm{eV}$ arose from the amide group after chemical conjugation of $\mathrm{ND} / \mathrm{ND} / \mathrm{MoS}_{2}$ nanocomposites. After chemical conjugation between ND-COCl and amine-functionalized $\mathrm{MoS}_{2}$, the intensity of the peak at $286.0 \mathrm{~V}(\mathrm{C}-\mathrm{O})$ increased significantly relative to that of the peak at $287.2 \mathrm{~V}(\mathrm{C}=\mathrm{O})$. The results indicate that unreacted acyl chloride would decompose into carboxyl groups during the washing process and from contact with moisture. The $\mathrm{O} 1$ peaks of $\mathrm{ND}-\mathrm{COCl}$ and $\mathrm{ND} / \mathrm{MoS}_{2}$ at 531.8 and $533.1 \mathrm{eV}$ were attributed to $\mathrm{C}=\mathrm{O}$ and $\mathrm{COC} / \mathrm{COH}$, respectively. The intensity of the ND/MoS 2 peak increased relative to that of the ND-COCl peak, indicating that the unreacted acyl chloride group was converted to the carboxyl group after chemical conjugation with the $\mathrm{MoS}_{2}$ nanosheets (Figure $3 \mathrm{~b}, \mathrm{e}$ ). The $\mathrm{Cl} 2 \mathrm{p}$ peaks of the ND-COCl were deconvoluted into two conventional binding energies of $200.3 \mathrm{eV}\left(\mathrm{Cl}_{2} \mathrm{p}_{3 / 2}\right)$ and $201.9 \mathrm{eV}\left(\mathrm{Cl} 2 \mathrm{p}_{1 / 2}\right)$. This indicated that ND-COOH was functionalized by an acyl chloride group on the surface [36]. Deconvolution of the $\mathrm{Cl} 2 \mathrm{p}$ peaks, corresponding to $\mathrm{ND} / \mathrm{MoS}_{2}$ generated peaks at $200.3 \mathrm{eV}\left(\mathrm{Cl} 2 \mathrm{p}_{3 / 2}\right)$ and $201.9 \mathrm{eV}\left(\mathrm{Cl} \mathrm{2}_{1 / 2}\right)$, have resulted from the physical adsorption of remnant chloride ions onto the ND surface and nanocage $[34,36]$.

Figure 4 shows the XPS spectra of the $\mathrm{MoS}_{2}$ and ND/MoS 2 nanocomposite. Two strong peaks for the Mo 3d peak of $\mathrm{MoS}_{2}$ are observed at 229.85 for doublet Mo $3 \mathrm{~d}_{5 / 2}$ and $232.98 \mathrm{eV}$ for and Mo $3 d_{3 / 2}$ (Figure $4 a$ ). The peaks, corresponding to the $S 2 p_{1 / 2}$ and $S 2 p_{3 / 2}$ orbital of divalent sulfide ions $\left(\mathrm{S}_{2}-\right)$ occur at binding energies of 163.85 and $162.65 \mathrm{eV}$, respectively, as shown in Figure $4 \mathrm{~b}$. The results are consistent with the values reported for a $\mathrm{MoS}_{2}$ crystal [35,40-42]. The XPS spectra of ND/MoS also revealed typical $\mathrm{MoS}_{2}$ crystalline characteristics with chemically induced shifting. Furthermore, the peak position moved from 229.85 to $229.53 \mathrm{eV}$ for Mo $3 \mathrm{~d}_{5 / 2}$ and from 232.98 to $232.64 \mathrm{eV}$ for Mo $3 \mathrm{~d}_{3 / 2}$, respectively. Chemically induced shifts were also observed for ND/MoS $\mathrm{S} 2 \mathrm{p}$, with the peaks shifting from 162.65 to $162.44 \mathrm{eV}$ for $\mathrm{S} 2 \mathrm{p}_{3 / 2}$ and 163.85 to $163.71 \mathrm{eV}$ for $\mathrm{S} 2 \mathrm{p}_{1 / 2}$ peaks [43]. This indicated that the chemical shift of the ND/MoS 2 nanocomposite to lower binding energy than that of $\mathrm{MoS}_{2}$ resulted from chemical conjugation with ND. 

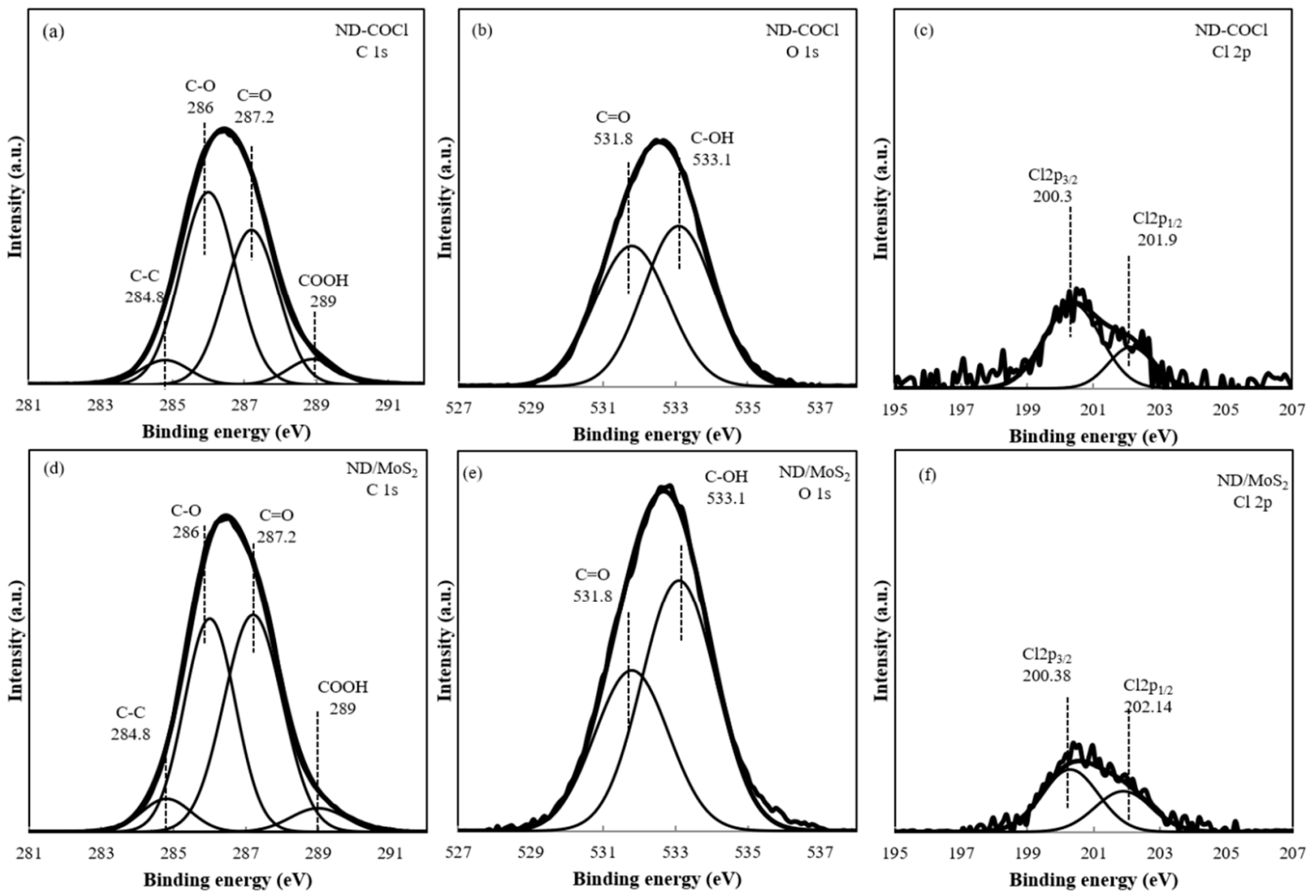

Figure 3. Spectra obtained via X-ray photoelectron spectroscopy. The spectra show the C1s peaks, O1s peaks, and $\mathrm{Cl} 2 \mathrm{p}$ peaks, respectively, of the (a)-(c) $\mathrm{ND}-\mathrm{COCl}$ and (d)-(f) $\mathrm{ND} / \mathrm{MoS}_{2}$ nanocomposites.
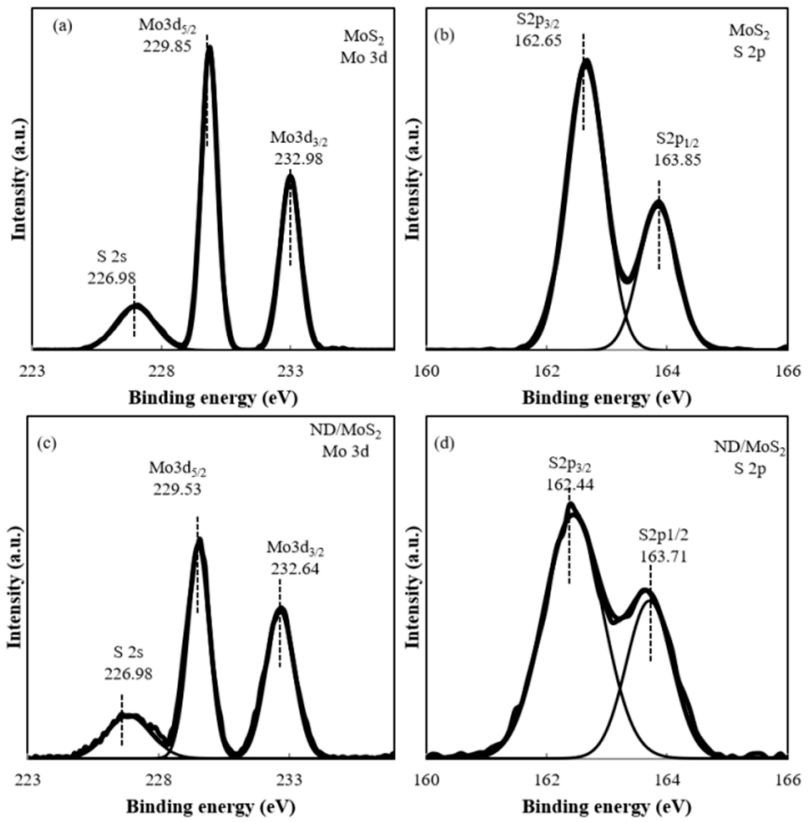

Figure 4. Spectra obtained via X-ray photoelectron spectroscopy. The spectra show Mo 3d peaks and S $2 p$ peaks of the (a)-(b) $\mathrm{MoS}_{2}$ nanosheets and (c)-(d) ND/MoS 2 nanocomposites.

The morphologies of $\mathrm{MoS}_{2}, \mathrm{ND}$, and ND/MoS 2 nanocomposites (Figure 5) were evaluated with TEM. The $\mathrm{MoS}_{2}$ nanosheets was featured as average size of 300-400 $\mathrm{nm}$ along the long axis (Figure 5a,b). The $\mathrm{MoS}_{2}$ nanosheets had a crystalline structure, and several molecular layers were stacked or folded in a planar form [44]. Furthermore, the NDs were well-dispersed with small agglutinins ranging from 80 to $200 \mathrm{~nm}$ (Figure 5c,d). The ND/MoS 2 nanocomposite with chemical conjugation showed morphological 
features that several molecular layers of thin $\mathrm{MoS}_{2}$ nanosheet enveloped ND agglutinins (Figure 5e-h). Amine-functionalized $\mathrm{MoS}_{2}$ nanosheets and NDCOCls were chemically reacted through surface contact, suggesting that the ND/MoS 2 nanocomposite was successfully synthesized (Figure 5e-h).
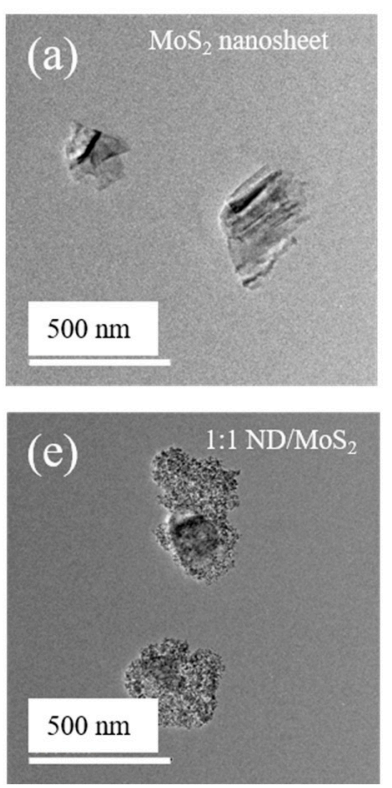
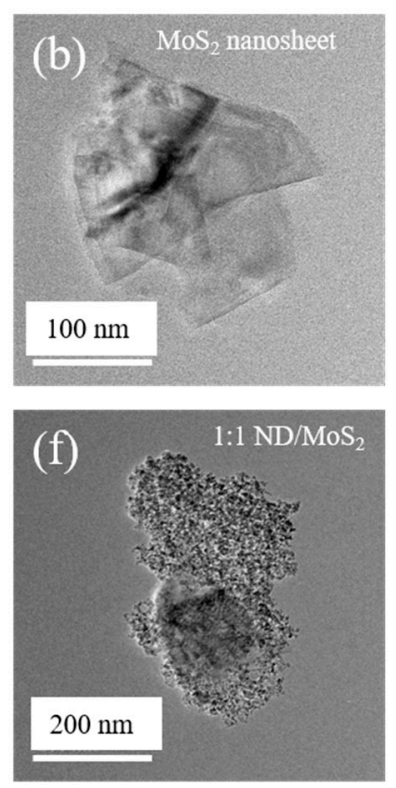
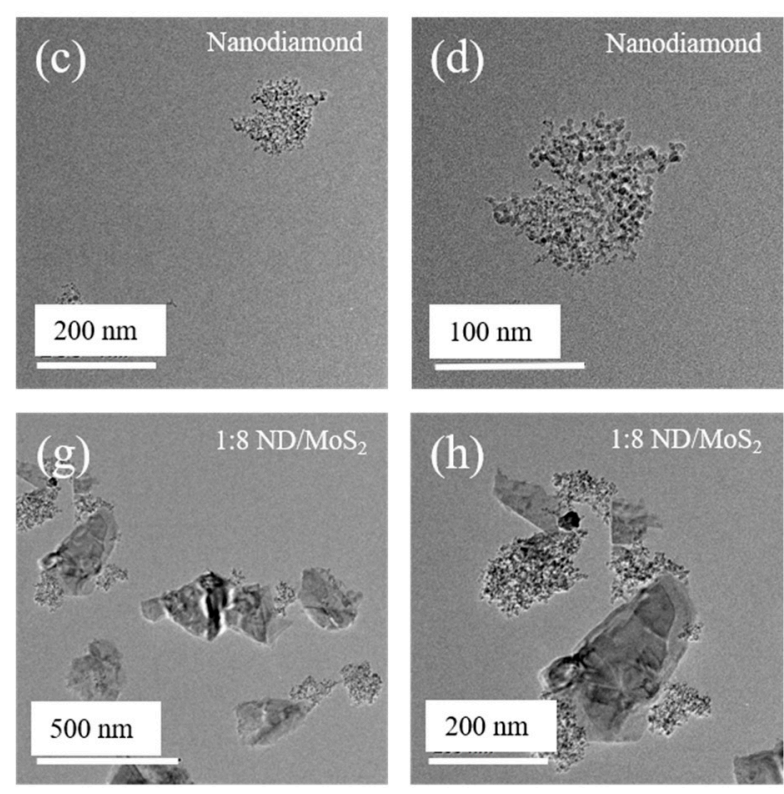

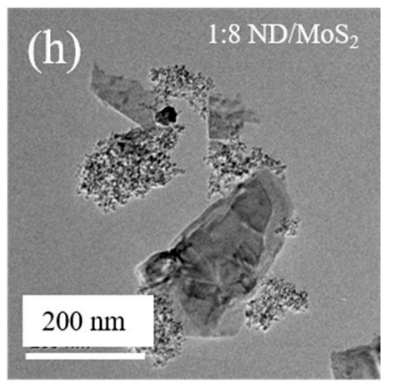

Figure 5. FE-TEM image of (a)-(b) $\mathrm{MoS}_{2}$ nanosheet, (c)-(d) ND, and (e)-(h) ND/MoS 2 nanocomposites.

Cyclic voltammograms of the $\mathrm{MoS}_{2}$ nanosheet and ND/MoS 2 are shown in Figure 6a-f. For both electrodes, the rectangularity of the $\mathrm{CV}$ plots decreased slightly, corresponding to the reversible reactions of $\mathrm{Mo}^{2+} / \mathrm{Mo}^{3+}$ associated with $\mathrm{OH}^{-}$anions [45]. The possible redox reaction is given as follows [46]:

$$
\begin{gathered}
\mathrm{ND} / \mathrm{MoS}_{2}+\mathrm{OH}^{-} \leftrightarrow \mathrm{ND} / \mathrm{MoSOH}+\mathrm{e}^{-} \\
\mathrm{ND} / \mathrm{MoSOH}+\mathrm{OH}^{-} \leftrightarrow \mathrm{ND} / \mathrm{MoSO}+\mathrm{H}_{2} \mathrm{O}+\mathrm{e}^{-}
\end{gathered}
$$

On the same material set, scan rates of $0.05,0.1$, and $0.5 \mathrm{~V} / \mathrm{s}$, respectively, and range of potential voltage was differently applied to -0.8 to $-0.2 \mathrm{~V}$ and -0.2 to $1.0 \mathrm{~V}$. The shape and magnitude of the voltamogram was transitioned from a peak-like shape (Figure $6 \mathrm{a}-\mathrm{c}$ ) to quasi-rectangular shape (Figure 6d-f) depending on the scan rate and potential voltage. The quasi-rectangular shape typically indicates constant and time dependent concentration gradient of an electroactive surface where the electrode radius was typically smaller than diffusion layer [47]. Each CV graph is characterized by a quasi-rectangular shape, consistent with dual behavior, such as the electrical double layer capacitance [48] $\mathrm{MoS}_{2}$ nanosheets constitute the minimum area of the CV plot, whereas 1:8 and 1:6 $\mathrm{ND} / \mathrm{MoS}_{2}$ constitutes the maximum area, which corresponds to the enhanced capacitance. The CV curve of the $\mathrm{ND} / \mathrm{MoS}_{2}$ nanocomposites reveals the higher current response and large working area of these composites, compared with those of the $\mathrm{MoS}_{2}$ nanosheet only (Figure 6). The results suggest that the addition of nanodiamonds enhances the electrochemical activity and increases the specific capacitance of $\mathrm{MoS}_{2}$ electrode alone [29,35].

The superior electrical performance of the $\mathrm{ND} / \mathrm{MoS}_{2}$ nanocomposite electrode, compared with that of the $\mathrm{MoS}_{2}$ electrode alone, resulted from the unique nanostructure of the composite electrode. Moreover, the large surface area and the nanosized $\mathrm{MoS}_{2}$ phase of the ND/MoS 2 composites may have resulted in significant reduction of the diffusion length associated with ion and electron transfer during the oxidation/reduction process. The electrode nanoscale phase makes these composites promising for various applications. Specifically, the NDs acted as nanoscale supports to functionalize synergistically the $\mathrm{MoS}_{2}$ sheets, which served as a three-dimensional highly conductive current collector. The featured architecture of the $\mathrm{ND} / \mathrm{MoS}_{2}$ nanocomposites possessing a large specific surface of the electrode 
enables rapid and simultaneous electron and ion transport, thereby leading to excellent electrochemical capacitive performance [42].
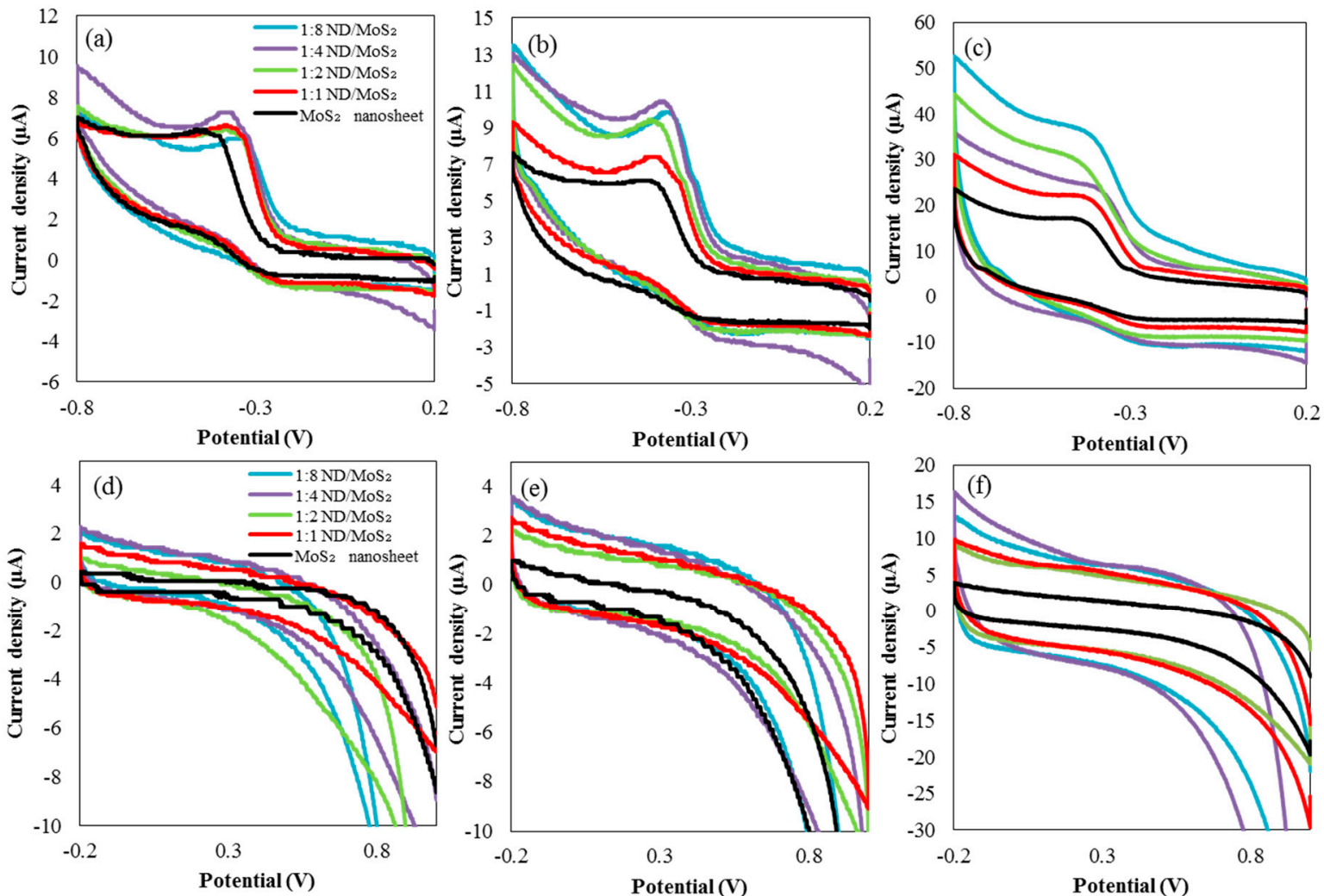

Figure 6. Cyclic voltammograms of the $\mathrm{MoS}_{2}$ nanosheet and $\mathrm{ND} / \mathrm{MoS}_{2}$ nanocomposite with ratio of $1: 1,1: 2,1: 4$, and 1:8. Scan rates of $0.05,0.1$, and $0.5 \mathrm{~V} / \mathrm{s}$ were employed for potentials ranging from (a) $-(\mathbf{c})-0.8$ to $0.2 \mathrm{~V}$ and $(\mathbf{d})-(\mathbf{f})-0.2$ to $1.0 \mathrm{~V}$.

\section{Conclusions}

A chemically conjugated ND/MoS 2 nanocomposite was synthesized with amine-functionalized $\mathrm{MoS}_{2}$ and acyl chloride-coordinated NDs. The chemical structure and morphology of the nanocomposite were characterized, and the results revealed that the $\mathrm{MoS}_{2}$ nanosheets were well-distributed on the ND platform, thereby forming a nanophase. Nanophase distribution of $\mathrm{MoS}_{2}$ on ND with a graphitic shell may provide a large surface area and reduce the diffusion distance of ions and electrons. Therefore, the augmented electrochemical capacitance of the nanophase electrode was induced, compared to that of the $\mathrm{MoS}_{2}$ electrode alone.

Author Contributions: For research articles was prepared and supported by conceptualization. S.Y.K.; data curation, D.L.; writing - original draft preparation, Y.K.; and supervision, E.K. and C.K.K.

Funding: This research was supported by Basic Science Research Program through the National Research Foundation of Korea (NRF) funded by the Ministry of Education (NRF-2018R1D1A1B07042982). This research was supported by the Chung-Ang University Research Scholarship Grants in 2018.

Conflicts of Interest: The authors declare no conflict of interest. 


\section{References}

1. Qiu, H.; Xu, T.; Wang, Z.L.; Ren, W.; Nan, H.Y.; Ni, Z.H.; Chen, Q.; Yuan, S.J.; Miao, F.; Song, F.Q.; et al. Hopping transport through defect-induced localized states in molybdenum disulphide. Nat. Commun. 2013, 4, 2642. [CrossRef] [PubMed]

2. Wu, S.F.; Huang, C.M.; Aivazian, G.; Ross, J.S.; Cobden, D.H.; Xu, X.D. Vapor-Solid Growth of High Optical Quality $\mathrm{MoS}_{2}$ Monolayers with Near-Unity Valley Polarization. Acs Nano 2013, 7, 2768-2772. [CrossRef] [PubMed]

3. Song, H.S.; Li, S.L.; Gao, L.; Xu, Y.; Ueno, K.; Tang, J.; Cheng, Y.B.; Tsukagoshi, K. High-performance top-gated monolayer $\mathrm{SnS}_{2}$ field-effect transistors and their integrated logic circuits. Nanoscale 2013, 5, 9666-9670. [CrossRef] [PubMed]

4. Xia, D.; Gong, F.; Pei, X.D.; Wang, W.B.; Li, H.; Zeng, W.; Wu, M.Q.; Papavassiliou, D.V. Molybdenum and tungsten disulfides-based nanocomposite films for energy storage and conversion: A review. Chem. Eng. J. 2018, 348, 908-928. [CrossRef]

5. Huang, L.F.; Gong, P.L.; Zeng, Z. Correlation between structure, phonon spectra, thermal expansion, and thermomechanics of single-layer $\mathrm{MoS}_{2}$. Phys. Rev. B 2014, 90, 045409. [CrossRef]

6. Sorkin, V.; Pan, H.; Shi, H.; Quek, S.Y.; Zhang, Y.W. Nanoscale Transition Metal Dichalcogenides: Structures, Properties, and Applications. Crit. Rev. Solid State 2014, 39, 319-367. [CrossRef]

7. Yang, X.; Meng, N.N.; Zhu, Y.C.; Zhou, Y.F.; Nie, W.W.; Chen, P.P. Greatly improved mechanical and thermal properties of chitosan by carboxyl-functionalized $\mathrm{MoS}_{2}$ nanosheets. J. Mater. Sci. 2016, 51, 1344-1353. [CrossRef]

8. Cheng, Y.; Pang, K.L.; Wu, X.; Zhang, Z.G.; Xu, X.H.; Ren, J.K.; Huang, W.; Song, R. In Situ Hydrothermal Synthesis MoS2/Guar Gum Carbon Nanoflowers as Advanced Electrocatalysts for Electrocatalytic Hydrogen Evolution. Acs Sustain. Chem. Eng. 2018, 6, 8688-8696. [CrossRef]

9. Haynes, K.; Murray, R.; Weinrich, Z.; Zhao, X.; Chiappe, D.; Sutar, S.; Radu, I.; Hatem, C.; Perry, S.S.; Jones, K.S. Modulating the resistivity of $\mathrm{MoS}_{2}$ through low energy phosphorus plasma implantation. Appl. Phys. Lett. 2017, 110, 262102. [CrossRef]

10. Wang, X.H.; Ding, J.J.; Yao, S.W.; Wu, X.X.; Feng, Q.Q.; Wang, Z.H.; Geng, B.Y. High supercapacitor and adsorption behaviors of flower-like $\mathrm{MoS}_{2}$ nanostructures. J. Mater. Chem. A 2014, 2, 15958-15963. [CrossRef]

11. Jing, Y.; Ortiz-Quiles, E.O.; Cabrera, C.R.; Chen, Z.F.; Zhou, Z. Layer-by-Layer Hybrids of $\mathrm{MoS}_{2}$ and Reduced Graphene Oxide for Lithium Ion Batteries. Electrochim. Acta 2014, 147, 392-400. [CrossRef]

12. Allen, M.J.; Tung, V.C.; Kaner, R.B. Honeycomb Carbon: A Review of Graphene. Chem. Rev. 2010, 110, $132-145$. [CrossRef] [PubMed]

13. Jiang, H.J. Chemical Preparation of Graphene-Based Nanomaterials and Their Applications in Chemical and Biological Sensors. Small 2011, 7, 2413-2427. [CrossRef] [PubMed]

14. Lee, J.H.; Park, S.J.; Choi, J.W. Electrical Property of Graphene and Its Application to Electrochemical Biosensing. Nanomaterials 2019, 9, 297. [CrossRef] [PubMed]

15. Yang, J.; Ma, M.Z.; Li, L.Q.; Zhang, Y.F.; Huang, W.; Dong, X.C. Graphene nanomesh: New versatile materials. Nanoscale 2014, 6, 13301-13313. [CrossRef]

16. Polcar, T.; Nossa, A.; Evaristo, M.; Cavaleiro, A. Nanocomposite coatings of carbon-based and transition metal dichalcogenides phases: A review. Rev. Adv. Mater. Sci. 2007, 15, 118-126.

17. Mohamed, M.M.; Ghanem, M.A.; Reda, S.M.; Khairy, M.; Naguib, E.M.; Alotaibi, N.H. Photovoltaic and capacitance performance of low-resistance $\mathrm{ZnO}$ nanorods incorporated into carbon nanotube-graphene oxide nanocomposites. Electrochim. Acta 2019, 307, 430-441. [CrossRef]

18. Suriyakumar, S.; Gopi, S.; Kathiresan, M.; Bose, S.; Gowd, B.; Nair, J.R.; Angulakshmi, N.; Meligrana, G.; Bella, F.; Gerbaldi, C.; et al. Metal organic framework laden poly(ethylene oxide) based composite. electrolytes for all-solid-state Li-S and Li-metal polymer batteries. Electrochim. Acta 2018, 285, 355-364. [CrossRef]

19. Shanker, G.S.; Markad, G.B.; Jagadeeswararao, M.; Bansode, U.; Nag, A. Colloidal Nanocomposite of TiN and N-Doped Few-Layer Graphene for Plasmonics and Electrocatalysis. Acs Energy Lett. 2017, 2, 2251-2256. [CrossRef]

20. Fu, W.B.; Zhao, E.B.; Ren, X.L.; Magasinski, A.; Yushin, G. Hierarchical Fabric Decorated with Carbon Nanowire/Metal Oxide Nanocomposites for 1.6 V Wearable Aqueous Supercapacitors. Adv. Energy Mater. 2018, 8, 1703454-1703462. [CrossRef] 
21. Mochalin, V.N.; Shenderova, O.; Ho, D.; Gogotsi, Y. The properties and applications of nanodiamonds. Nat. Nanotechnol. 2011, 7, 11-23. [CrossRef] [PubMed]

22. Lim, D.G.; Prim, R.E.; Kim, K.H.; Kang, E.; Park, K.; Jeong, S.H. Combinatorial nanodiamond in pharmaceutical and biomedical applications. Int. J. Pharmaceut. 2016, 514, 41-51. [CrossRef]

23. Mochalin, V.N.; Pentecost, A.; Li, X.M.; Neitzel, I.; Nelson, M.; Wei, C.Y.; He, T.; Guo, F.; Gogotsi, Y. Adsorption of Drugs on Nanodiamond: Toward Development of a Drug Delivery Platform. Mol. Pharmaceut. 2013, 10, 3728-3735. [CrossRef] [PubMed]

24. Yuan, T.; Larsson, K. Theoretical Study of Size Effects on Surface Chemical Properties for Nanoscale Diamond Particles. J. Phys. Chem. C 2014, 118, 26061-26069. [CrossRef]

25. Duffy, E.; He, X.Y.; Nesterenko, P.N.; Paull, B. Hierarchical porous graphitic carbon monoliths with detonation nanodiamonds: synthesis, characterisation and adsorptive properties. J. Mater. Sci. 2015, 50, 6245-6259. [CrossRef]

26. Lim, D.G.; Jung, J.H.; Ko, H.W.; Kang, E.; Jeong, S.H. Paclitaxel-Nanodiamond Nanocomplexes Enhance Aqueous Dispersibility and Drug Retention in Cells. Acs Appl. Mater. Interfaces 2016, 8, 23558-23567. [CrossRef] [PubMed]

27. Agarwal, V.; Chatterjee, K. Recent advances in the field of transition metal dichalcogenides for biomedical applications. Nanoscale 2018, 10, 16365-16397. [CrossRef]

28. Kim, C.; Nguyen, T.P.; Le, Q.V.; Jeon, J.-M.; Jang, H.W.; Kim, S.Y. Performances of Liquid-Exfoliated Transition Metal Dichalcogenides as Hole Injection Layers in Organic Light-Emitting Diodes. Adv. Funct. Mater. 2015, 25, 4512-4519. [CrossRef]

29. Azhagan, M.V.K.; Vaishampayan, M.V.; Shelke, M.V. Synthesis and electrochemistry of pseudocapacitive multilayer fullerenes and $\mathrm{MnO} 2$ nanocomposites. J. Mater. Chem. A 2014, 2, 2152-2159. [CrossRef]

30. Zhao, W.J.; Ghorannevis, Z.; Chu, L.Q.; Toh, M.L.; Kloc, C.; Tan, P.H.; Eda, G. Evolution of Electronic Structure in Atomically Thin Sheets of WS2 and WSe2. Acs Nano 2013, 7, 791-797. [CrossRef]

31. Muscuso, L.; Cravanzola, S.; Cesano, F.; Scarano, D.; Zecchina, A. Optical, Vibrational, and Structural Properties of MoS2 Nanoparticles Obtained by Exfoliation and Fragmentation via Ultrasound Cavitation in Isopropyl Alcohol. J. Phys. Chem. C 2015, 119, 3791-3801. [CrossRef]

32. Rao, C.N.R.; Maitra, U.; Waghmare, U.V. Extraordinary attributes of 2-dimensional MoS2 nanosheets. Chem. Phys. Lett. 2014, 609, 172-183. [CrossRef]

33. Mishra, A.K.; Lakshmi, K.V.; Huang, L.P. Eco-friendly synthesis of metal dichalcogenides nanosheets and their environmental remediation potential driven by visible light. Sci. Rep.-Uk 2015, 5, 15718. [CrossRef] [PubMed]

34. Lim, D.G.; Kim, K.H.; Kang, E.; Lim, S.H.; Ricci, J.; Sung, S.K.; Kwon, M.T.; Jeong, S.H. Comprehensive evaluation of carboxylated nanodiamond as a topical drug delivery system. Int. J. Nanomed. 2016, 11, 2381-2395.

35. Ramadoss, A.; Kim, T.; Kim, G.S.; Kim, S.J. Enhanced activity of a hydrothermally synthesized mesoporous MoS2 nanostructure for high performance supercapacitor applications. New J. Chem. 2014, 38, 2379-2385. [CrossRef]

36. Lim, D.G.; Rajasekaran, N.; Lee, D.; Kim, N.A.; Jung, H.S.; Hong, S.; Shin, Y.K.; Kang, E.; Jeong, S.H. Polyamidoamine-Decorated Nanodiamonds as a Hybrid Gene Delivery Vector and siRNA Structural Characterization at the Charged Interfaces. Acs Appl. Mater. Interfaces 2017, 9, 31543-31556. [CrossRef]

37. Shenderova, O.; Panich, A.M.; Moseenkov, S.; Hens, S.C.; Kuznetsov, V.; Vieth, H.M. Hydroxylated Detonation Nanodiamond: FTIR, XPS, and NMR Studies. J. Phys. Chem. C 2011, 115, 19005-19011. [CrossRef]

38. Choi, E.Y.; Kim, C.K. Fabrication of nitrogen-doped nano-onions and their electrocatalytic activity toward the oxygen reduction reaction. Sci. Rep.-Uk 2017, 7, 4178. [CrossRef]

39. Kamila, S.; Mohanty, B.; Samantara, A.K.; Guha, P.; Ghosh, A.; Jena, B.; Satyam, P.V.; Mishra, B.K.; Jena, B.K. Highly Active 2D Layered $\mathrm{MoS}_{2}$-rGO Hybrids for Energy Conversion and Storage Applications. Sci. Rep.-Uk 2017, 7, 8378. [CrossRef]

40. Minakshi, M.; Barmi, M.J.; Jones, R.T. Rescaling metal molybdate nanostructures with biopolymer for energy storage having high capacitance with robust cycle stability. Dalton Trans. 2017, 46, 3588-3600. [CrossRef]

41. Barmi, M.J.; Minakshi, M. Tuning the Redox Properties of the Nanostructured CoMoO4 Electrode: Effects of Surfactant Content and Synthesis Temperature. Chempluschem 2016, 81, 964-977. [CrossRef] 
42. Ganguly, A.; Sharma, S.; Papakonstantinou, P.; Hamilton, J. Probing the Thermal Deoxygenation of Graphene Oxide Using High-Resolution In Situ X-ray-Based Spectroscopies. J. Phys. Chem. C 2011, 115, 17009-17019. [CrossRef]

43. Gao, D.Q.; Si, M.S.; Li, J.Y.; Zhang, J.; Zhang, Z.P.; Yang, Z.L.; Xue, D.S. Ferromagnetism in freestanding $\mathrm{MoS}_{2}$ nanosheets. Nanoscale Res. Lett. 2013, 8, 129-136. [CrossRef] [PubMed]

44. Lee, H.; Kim, H.; Nguyen, T.P.; Chang, J.H.; Kim, S.Y.; Kim, H.; Kang, E. Nanocomposites of Molybdenum Disulfide/Methoxy Polyethylene Glycol-co-Polypyrrole for Amplified Photoacoustic Signal. Acs Appl. Mater. Interfaces 2016, 8, 29213-29219. [CrossRef] [PubMed]

45. Cheng, Q.; Tang, J.; Ma, J.; Zhang, H.; Shinya, N.; Qin, L.C. Graphene and nanostructured $\mathrm{MnO}_{2}$ composite electrodes for supercapacitors. Carbon 2011, 49, 2917-2925. [CrossRef]

46. Kumuthini, R.; Ramachandran, R.; Therese, H.A.; Wang, F. Electrochemical properties of electrospun $\mathrm{MoS}_{2} @ \mathrm{C}$ nanofiber as electrode material for high-performance supercapacitor application. J. Alloys Compd. 2017, 705, 624-630. [CrossRef]

47. Mirčeski, V.; Tomovski, Z. Voltammetry Based on Fractional Diffusion. J. Phys. Chem. B 2009, 113, $2794-2799$. [CrossRef]

48. Ramkumar, R.; Sundaram, M.M. Electrochemical synthesis of polyaniline crosslinked $\mathrm{NiMoO}_{4}$ nanofibre dendrites for energy storage devices. New J. Chem. 2016, 40, 7456-7464. [CrossRef]

(C) 2019 by the authors. Licensee MDPI, Basel, Switzerland. This article is an open access article distributed under the terms and conditions of the Creative Commons Attribution (CC BY) license (http://creativecommons.org/licenses/by/4.0/). 